\title{
Evidence of Information Asymmetry and Herding Behaviour - The Swiss Franc Unpegging Event in Perspective
}

\author{
Shruti Garg*
}

\section{Abstract}

The paper aims to find the impact of financial events that occurred in one country on another country. The paper takes Swiss Franc Unpegging, 2015 that happened in Switzerland and observes its impact on Indian economy. The impact is observed through information asymmetry and herding behaviour in Indian market on the day of the event. This study uses two sets of data, one is high frequency data and the other set of data comprises 3 years index data of both the countries. The impact on any country can be studied only if there is a cause and effect relationship between the economies, for which the paper also conducts Ganger Causality test. The study found herding behaviour and information asymmetry in Indian market are now linked to each other in such a way that the country is affected even if the event has not occurred in the economy itself. However, it has been observed that the effect persists only for a short duration. This study helps to find out the effect of Swiss Franc unpegging in the Indian market. It aims to find the information asymmetry and herding behaviour on the event day in the Indian market. The investors are found to have a huge gap between the information available amongst all. Herding behavior is mostly seen in the Indian market when the market goes up and is found in the study also.

* Risk Associate, Thomson Reuters, Bangalore; shrutigarg612@gmail.com 
Keywords: Hill Estimator, Hurst Exponent, Granger Causality, Information Asymmetry, Herding, Swiss Franc Unpegging, Fat-Tail Event

\section{Introduction}

India and Switzerland have a special and long haul collaboration that is animated by energetic vote based customs, qualities and regular interests.

On January 15, when the Swiss National Bank (SNB) out of nowhere reported that it would never again hold the Swiss franc at a fixed swapping scale with the euro, it created unrest in the Indian securities exchange and the franc's value went up. At a certain point; one euro was worth 1.2 Swiss francs; at another, its worth dropped to 0.85 francs. Various flexible investments around the globe have made immense misfortunes. The Swiss financial exchange crumbled. The SNB presented the conversion scale in 2011, while the monetary markets far and wide were in strife. Speculators view the Swiss franc as a "place of refuge" resource, alongside US government securities: get them and you realize your cash won't be undermined. A lot of speculators speculate on Swiss Franc currency as the Swiss government builds a decent spending plan for the country. This makes the speculator to trust the Swiss Government and use it for their strategy For instance, as financial specialists pulled in Francs, they drastically pushed its worth. A costly franc harms Switzerland because the economy is vigorously dependent on selling merchandise abroad: fares of products and ventures are worth over $70 \%$ of GDP. To decrease the estimation of the franc, the SNB made new francs and utilized them to purchase Euros. The expansion in the general inventory of euro francs in the remote trade markets estimated the franc fall (consequently verifying one euro was worth 1.2 francs). Due to this strategy, by 2014 the SNB had gathered about $\$ 480$ billion in remote money, identical to about $70 \%$ of Swiss GDP.

The strategy made the Swiss Franc to fall and SNB to gain a huge amount of money which can end hyperinflation in Swiss economy. These apprehensions are presumably unwarranted: Swiss swelling is exceptionally low. Be that as it may, this is an important political 
issue. Many anticipate that the European Central Bank should present "quantitative facilitating". This requires the making of cash to purchase open obligation in euro-region nations. This will build the estimation of the euro, which may require SNB to put many more francs to keep the cutoff. Be that as it may, there is a third purpose behind SNB's choice. In 2014, the euro devalued against other significant monetary standards. Subsequently, the franc (climbing the euro) likewise lost worth: in 2014 it lost around 12\% of its incentive against the dollar and 10\% against the rupee (although it was acknowledged against the two monetary forms after the SNB choice). The less expensive franc builds fares to America and India, which together record for around 20\% of Swiss fares. SNB contends that if the Swiss franc isn't so high, there is no motivation to debilitate it further.

\section{Literature Review}

Analysts concentrating on securities exchanges can be extensively characterized into conventionalists or money related business analysts who have to a great extent applied Gaussian irregular walk based measurable strategies in considering explicit financial exchange marvels, and econophysicists who have, rather, applied reasonable hypotheses of material science, including quantum physical science, to contemplate securities exchange conduct (Parkinson, 1980). The probability of data disease instigates benefit augmenting bank proprietors to group with different banks. The moment when it becomes hard for bank to recover loan, the cost of borrowing increases. This unfavourable news passes on in the market making more difficult for bankers to recover loan on normal factors. This motivates the borrowers to not to repay the loan and hence motivate herding. Acharya \& Yorulmazer (2019) consider this channel of herding behavior to reciprocate the benefit to banks even if they are profit making or expanding. Utilizing week after week information has likewise seen that crowding is a fleeting wonder and it isn't evident in the Indian financial exchange (Kumar, Bharti \& Bansal, 2018). Nevertheless, trading volume positively affects the conditional volatility in the Miscellaneous sector; Gibrat (1931) suspect that educated dealers are moderately less right now, the speculators can't separate educated from 
ignorant brokers; in this way, higher exchanging on explicit stocks is less perceptible, and the unpredictability of the normal part return turns out to be decidedly influenced by the volume turnover. Bensaïda (2017) saw that crowding contrarily influences the contingent instability of the normal segment returns in 10 areas, barring Capital merchandise and Consumer durables, where, even though the $\gamma$ coefficients comparative with CSAD are negative, they are as yet unimportant. For the volume turnover, it contrarily influences the instability in 5 areas other than the entire market. Evangelista \& Segovia (2017) have suggested a model that performs better when the portfolio has at least ten assets and the quantity increases. One regular element of ongoing cash emergencies has been the solid deviation of the conversion scale from basics, in this way setting off a high swapping scale of unpredictability (Belke \& Setzer, 2004). A similar rationale ought to apply to different markets with genius attributes: lofts with a huge perspective on Central Park in New York City, and top competitors in sports and the cost of renowned centrepieces. One result according to Gabaix (2016) is that pay in the total is tied in with remunerating ability, not tied in with paying for hazard and motivating forces (which influence pay in the cross-area, not in the total). In total, the compensation ability completely administers the degree of anticipated compensation; motivation issues are very auxiliary and nail down the type of pay, similar to what part is in fixed or variable compensation.

By investigating the Dynamic Conditional Correlations (DCC) of the day by day stock returns of four OECD nations with that of the US for the period 2006-2010, Min \& Hwang (2012) discovered a procedure of expanding relationships (disease) in the principal period of the US budgetary emergency and an extra increment of connections (grouping) during the second period of the US money related emergency for the UK, Australia, and Switzerland. Generally expressed, the arbitrary factors (r.v.) speaking to the distinctive stock costs in a single month and are said to be comonotonic on the off chance that they move as one and carry on like a solitary resource, not taking into account any enhancement (Linders, Dhaene \& Schoutens, 2015). Stock costs will ordinarily not move in an ideal comonotonic path and in that capacity, a financial exchange isn't showing impeccable crowd conduct. Dungey \& 62 
Tambakis (2003) discovered that money related emergencies and disease are inherently connected and that infectious impacts emerge when emergencies are proliferated across nations or markets in the wake of controlling for crucial linkages and interdependencies. Additionally, these transmissions may spread further through components, for example, cross-advertise supporting. According to Ormos \& Imotity (2016), results can be credited to an expansion in ignorant liquidity exchanging yet not to heuristic-driven (or contrarian) exchanging. New models will without a doubt be required with the approach of new emergencies. Be that as it may, a portion of the striking angles illustrated right now is liable to repeat. These include the principal linkages, the methods for transmission across nations and resource classes, the factual properties of the information, the synchronous recognizable proof of infection, interdependency and crowding and the endogenous distinguishing proof of emergency and nonemergency periods from the test information (Nirei, Stachurski \& Stachurski, 2018).

Seeing how a financial crash happens is a significant issue in econophysics. Redelico \& Proto (2012) in the experimental proof of a multifractal signature for the expanding return time of a money related air pocket before an accident examined to give a geometric depiction of return variances during this period. Zhang \& Huang (2010) characterized wave capacities and administrators of the financial exchange to set up the Schrödinger condition at the stock cost. In numerous fields, there is solid proof that a wonder called "long memory" assumes a noteworthy job, with suggestions for gauge aptitude, low recurrence varieties, and patterns. In a stationary time arrangement, the expression "long memory" - once in a while "long-range reliance" (LRD) or "long haul perseverance" - suggests that there is non-insignificant reliance between the present and all previous focuses. Specifically, it is critical to test if a procedure is displaying long memory since that affects the exactness and certainty with which one may anticipate future occasions based on a limited quantity of chronicled information (Hurst, 1951). Gneiting \& Schlather (2001) presented basic stochastic models which separate fractal measurement and Hurst coefficient and take into account any mix of the two parameters. The Hurst impact in hydrology is entrenched and for 
the most part, perceived as a significant property of how nature functions (Mandelbrot, 1970). It is generally estimated that utilizing rescaled extended investigation in which the normal scope of the total of deviations from the mean in sub-tests, standardized by the standard deviation, fills in as a proportion of tirelessness in the information. Watkins \& Franzke (2017) have endeavoured to show the first inspiration driving long memory procedures, and follow the early development of the idea of long memory, from the mid1950 s to the late 1970 s.

The power-law perspective begins by noting that large institutions are roughly Zipf distributed (Hill, 1975), so when they trade, they could have a very large price impact. The model is based on a pure jump Levy process, wherein the arrival rate of jumps obeys a power law dampened by an exponential function. Bachelier's trailblazing arbitrary walk model (enlivened from the Brownian movement of particles) had a suspicion, for example, the value changes develop because of numerous autonomous and outer stuns (Bachelier, 1900). The return on assets tend to converge as the time aggregates. This is because of the focal breaking point hypothesis $(\mathrm{Wu}, 2006)$. The Tail exponent or $a \approx 3$, is found to be well outside the Levy regime $(0<\alpha<2)$ (Fama, 2008). Risk (volatility proxy) and return (log returns) being two indivisible segments of the quantitative fund have been found to observe the comparable law too. Subsequently, converse cubic law genuinely gets all-inclusive in quantitative money (Ghosh \& Krishna, 2019). Botta, Moat, Stanley, \& Preis (2015) results are steady with the speculation that adjustments in securities exchange costs have various practices at various time scales. As it were, enormous changes will, in general, be trailed by huge changes of either sign and little changes will, in general, be trailed by little changes, so that the isolines of a low likelihood of $[\mathrm{L}(\mathrm{t}, 1), \mathrm{L}(\mathrm{t}-1,1)]$ are $\mathrm{X}$-formed. Such an $\mathrm{X}$ shape can be effectively gotten by revolution from the "in addition to sign shape" (Mandelbrott, 2009). The monetary Reynolds number (portraying unstable components in stock files) in the HighFrequency Trading (HFT) section of CNX NIFTY has been seen as progressively unsurprising, less unpleasant in structure and increasingly inclined to herd behaviour (Ghosh, Mc, Kozarevic \& Pandey, 2018). The previous work of Ghosh \& Kozarevic (2018) rationally linked with valid logic and backed up by a strong 64 
measuring tool to identify and formulate an apt econophysics proxy (read as financial Reynolds number) for volatility number (explosive number) and further predicting the number for future as well.

It is essential to look for unpredictability levels during the financial crisis and the post-crisis time. Moreover, the idea of entropy (Shannon's estimation) has been utilized to look at whether the instability of a stochastic time arrangement can be caught or not. In the bullish market scenario, people are likely to put funds in stock which have beta more than 2 . These types of stocks turn out to be less risky and yield high returns i.e. suitable for all. During bearish markets the same stocks become unapproachable and can term this as subjective inclination connected with heuristic improvement (Ghosh \& Nisha, 2018). The medium silliness gathering, as depicted in this, has the most elevated Hurst example and Shannon entropy among all the mindless gatherings for any money related arrangement, which demonstrates that the conduct of this gathering shows the most noteworthy unpredictability and helplessness (Kim \& Kim, 2014). The principle bit of leeway of the MF-DFA strategy contrasted and the WTMM technique lies in the straightforwardness of the MF-DFA strategy (Kantelhardt et al., 2002). While this is valid at each progression of the emphasis it turns out to be bogus when setting off as far as possible furthermore controlling the relationship structure of the exponentiated procedure is unwieldy and not constantly feasible (Riedi, 1999). Ghorbel, Boujelbene \& Boujelbene (2014) finds solid proof of bidirectional unpredictability transmission between the oil market and financial exchanges of oil-bringing in and oil-sending out nations in ARCH impact and additionally in GARCH impact. In light of the Moving Normal (MA) system for evaluating the Hurst type of self-affinity signals, the Detrending Moving Average (DMA) examination thinks about the distinction between the first sign and its moving normal capacity (Jiang, Xie, Zhou \& Sornette, 2018). They also indicate a clear link with Hausdorff topological patterns (Hausdorff, 1918). These examples would assist with making heuristics, empowering financial specialists to know about conceivable air pocket and group circumstances. Actually, the relationship got more grounded with multifractal estimation when contrasted with its monofractal pattern (the Hurst example became 
0.77 from 0.72)(Ghosh \& Kozarevic, 2019). The spatial and temporal variations indicate a multifractal structure of the biomedical signal that is defined by a multifractal spectrum of power law exponents (Ihlen, 2012).

\section{Objectives}

The paper tries to find two major behaviours of investors on the day of $15^{\text {th }}$ January 2015 . First, the authors intend to know whether the information of Swiss Franc unpegging was uniformly distributed to all the investors in India and secondly the rationality of investors on that particular day. Therefore, based on the above ideology the authors formulate three following objectives for our study -

i. To quantify the correlation between the two countries involved in the fat tail event

ii. To study information asymmetry among investors in India on $15^{\text {th }}$ January' 15

iii. To study herding behaviour of investors on the event of Swiss franc unpegging

\section{Research Methodology}

The data collected for this study is a high-frequency data of the NIFTY 50 index on $15^{\text {th }}$ January, the day on which the concerned event occurred. The data collected captures tick by tick change in the index. The benefit of taking high-frequency data is to capture the asymptotic decay in the falling index value. The events which cause fall of value in a fraction of second, their data for years or even a day become meaningless as the large data will not be able to retain the effect caused by the event. The unpegging event had an impact on the index for a short period and hence high-frequency data was preferred. 


\begin{tabular}{|l|l|l|l|l|l|l|l|l|l||}
\hline 8274.05 & 8264.15 & 8260.70 & 8260.00 & 8256.95 & 8268.95 & 8269.45 & 8266.45 & 8270.60 & 8270.25 \\
8268.55 & 8263.45 & 8260.50 & 8259.45 & 8257.45 & 8269.20 & 8269.55 & 8267.20 & 8270.90 & 8270.10 \\
8267.85 & 8262.75 & 8260.35 & 8259.30 & 8257.10 & 8269.25 & 8270.05 & 8267.40 & 8269.50 & 8268.80 \\
8266.75 & 8261.25 & 8259.90 & 8259.40 & 8258.25 & 8271.10 & 8270.95 & 8267.60 & 8269.35 & 8268.85 \\
8265.60 & 8260.75 & 8259.90 & 8259.15 & 8258.10 & 8270.85 & 8270.70 & 8268.10 & 8269.75 & 8269.05 \\
8266.10 & 8260.20 & 8260.10 & 8257.95 & 8260.05 & 8270.05 & 8270.55 & 8267.75 & 8270.70 & 8268.60 \\
8264.35 & 8260.05 & 8259.85 & 8257.45 & 8259.55 & 8269.55 & 8271.20 & 8267.85 & 8270.50 & 8268.60 \\
8263.80 & 8260.00 & 8260.05 & 8256.60 & 8260.10 & 8269.60 & 8270.80 & 8267.55 & 8270.95 & 8268.30 \\
8265.80 & 8259.40 & 8258.90 & 8256.85 & 8260.25 & 8270.00 & 8271.00 & 8267.50 & 8270.80 & 8268.00 \\
8261.50 & 8259.05 & 8259.00 & 8256.85 & 8260.45 & 8269.55 & 8270.80 & 8267.35 & 8269.95 & 8267.10 \\
8262.30 & 8258.30 & 8259.10 & 8254.50 & 8261.05 & 8269.65 & 8271.50 & 8267.70 & 8270.35 & 8268.05 \\
8259.95 & 8257.25 & 8258.15 & 8252.20 & 8261.10 & 8269.10 & 8271.45 & 8268.65 & 8270.30 & 8267.90 \\
8256.15 & 8256.50 & 8259.05 & 8251.75 & 8261.10 & 8270.85 & 8271.50 & 8268.35 & 8271.10 & 8267.80 \\
8256.30 & 8255.35 & 8259.70 & 8251.50 & 8260.50 & 8271.60 & 8271.30 & 8268.65 & 8270.85 & 8267.15 \\
8254.95 & 8255.15 & 8260.80 & 8251.00 & 8259.85 & 8272.10 & 8271.90 & 8269.30 & 8271.35 & 8266.90 \\
8254.75 & 8254.60 & 8260.70 & 8250.85 & 8260.10 & 8271.15 & 8271.90 & 8269.45 & 8271.50 & 8267.35 \\
8254.85 & 8253.75 & 8260.55 & 8250.65 & 8260.80 & 8271.40 & 8271.95 & 8269.50 & 8270.85 & 8267.35 \\
8254.30 & 8254.00 & 8260.55 & 8251.70 & 8261.45 & 8271.90 & 8271.95 & 8269.60 & 8272.50 & 8267.25 \\
8254.55 & 8254.00 & 8260.70 & 8251.95 & 8261.70 & 8271.60 & 8271.80 & 8269.45 & 8273.15 & 8267.60 \\
\hline
\end{tabular}

Fig: 1 Sample of Nifty 50 High Frequency Data

The above figure shows a sample of high-frequency data collected from the NIFTY 50 index. The total observations taken were 8352 in just 15 mins of stamping. This helped us to find the hidden decay of the index on the event day. This data was processed in MATLAB to find information asymmetry and herding behaviour. Further, the data was also collected to find the correlation between the two countries i.e. India and Switzerland. The data used for this was a regular BSE and SMI index data, collected for 3 years from 2013 2016.

\begin{tabular}{|c|c|c|c|}
\hline Date & SMI & Date & BSECIOSe \\
\hline $2013-01-03$ & 7020.460 & $2013-01-03$ & 19714.240 \\
$2013-01-04$ & 7058.920 & $2013-01-04$ & 19764.779 \\
$2013-01-07$ & 7049.300 & $2013-01-07$ & 19784.080 \\
$2013-01-08$ & 7074.520 & $2013-01-08$ & 19691.420 \\
$2013-01-09$ & 7151.600 & $2013-01-09$ & 19742.520 \\
$2013-01-10$ & 7143.730 & $2013-01-10$ & 19666.590 \\
$2013-01-11$ & 7188.220 & $2013-01-11$ & 19663.551 \\
$2013-01-14$ & 7202.520 & $2013-01-14$ & 19663.641 \\
$2013-01-15$ & 7272.310 & $2013-01-15$ & 19906.410 \\
$2013-01-16$ & 7304.850 & $2013-01-16$ & 19986.820 \\
$2013-01-17$ & 7429.890 & $2013-01-17$ & 19817.631 \\
$2013-01-18$ & 7368.800 & $2013-01-18$ & 19964.029 \\
$2013-01-21$ & 7336.050 & $2013-01-21$ & 20039.039 \\
$2013-01-22$ & 7291.850 & $2013-01-22$ & 20101.820 \\
$2013-01-23$ & 7391.950 & $2013-01-23$ & 19981.570 \\
\hline $2013-01-24$ & 7457.740 & $2013-01-24$ & 20026.609 \\
$2013-01-25$ & 7458.660 & $2013-01-25$ & 19923.779 \\
$2013-01-28$ & 7483.950 & $2013-01-28$ & 20103.529 \\
$2013-01-29$ & 7458.030 & $2013-01-29$ & 20103.350 \\
\hline
\end{tabular}

Fig: 2 Sample of BSE and SMI Index 
Large data is needed to calculate the correlation between the two countries. The relation between these two countries is also strengthened by establishing their bilateral trade relationships.

The correlation between the two countries is found out numerically by Granger Causality. This method helps to find out the driving and driven country. The causality test by Granger considers a fundamental concept for detecting time-varying causal relationships between time series in economics and finance. This fundamental concept is defined in terms of predictability at the horizon one of a variable from its past and the past of another variable of auxiliary variables. The traditional linear Granger Causality tests within the linear autoregressive model class have been developed in many directions to detect causal relations between time series but they are limited in their capability to detect non-linear causality. Kyle \& Obizhaeva (2019) has briefly define linear Granger Causality in a VAR system to explore informational linkages between pairs of markets. Given any two stationary data pairs, say $X_{t}$ and $Y_{t}$, variable $X_{t}$ Granger causes $Y_{t}$ linearly provided that lags of $X_{t}$ offer significant information for explaining the current values of $Y_{t}$. The bivariate Granger causality is specified in a VAR system as follows:

$$
X_{i}=\hat{\gamma}_{1}+\sum_{i=1}^{k} a_{1 i} X_{t-i}+\sum_{j=1}^{k} b_{1 j} Y_{t-j}+\nu_{1 t}
$$

and

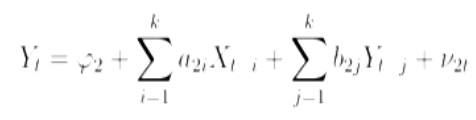

where $\varphi_{1}$ and $\varphi_{2}$ are the constant terms of the system of the equation; $a$ and $b$ denote estimated coefficients; $k$ is the optimal lag length based on the Akaike Information Criterion (AIC); and $v_{1 t}$ and $v_{2 t}$ represent residuals from the VAR model. Here for our study, we have taken India and Switzerland index as $X_{t}$ and $Y_{t}$ respectively to find out the driver and driven economy.

After establishing a correlation between the two countries the next important task is to find out the extent of the reach of information of the event among the Indian investors. This can be found out 
using Hill Estimator. Hill estimator is no newcomer to the world of tail risk identification; MIT professors Jansen \& Vries (1991) have applied the Hill estimator to daily returns of the US stocks and the stock indices for a substantial length of time (from 1962 to 1986). They've found estimates for the tail index a within the range of 3.25.2. Many research projects of the past have successfully found an inverse cubic law in the fat tail part of the distribution of stock market returns. Market volatility has been put into test and inverse cubic law was found to exist in the fat tails. Hill estimator has been deployed here to estimate the tail exponent a with an asymptotic power-law connection. In reality, Gaussian distributions are rare to find. Most distributions are found with fat tails in financial markets. Each tail (both positive and negative) comes up with its tail probabilities. Tail probabilities are generally defined in three categories, namely Medium Tailed, Fat Tailed and Thin Tailed. This is primarily done by the function, defined as the survival or tail probability function. It has been an existing knowledge that kurtosis ' $\mathrm{k}$ ' of an entirely stochastic variable ' $\mathrm{x}$ ' stands as a measurement of dispersion around the two extreme values, $\mu^{+-\sigma}$ where $\mu$ is the mean expected value and $\sigma$ remains as the standard deviation of ' $x$ '. In a typical Gaussian distribution, ' $k$ ' remains in and around the close vicinity of ' 3 '. Higher ' $k$ ' indicates more mass in the tails. Hence, for all types of risk management purposes, it becomes quite essential to track. It would be interesting to note that 'extreme value theory' is linked to very high values of ' $k$ '. Under such circumstances, an extreme deviation from the mean has been observed. This indicates an asymptotic distribution of extreme order statistics (Ghosh \& Krishna, 2019). The closer the value of alpha towards 3 shows there is information asymmetry, which means that the information was not uniformly distributed amongst all the investors. It has been observed in the past that certain power-law converges very quickly hence for most of the regime the power-law is a good approximation. However, in many instances, the power-law converges very slowly. It may produce a pseudo accurate result unless there is a very large sample of data. Recent studies have achieved this precision of prediction (asymptotic decay) by studying high-frequency data, rather welcomingly involving millions of observations (Farmer \& Geanakoplos, 2011). 
The following target of the investigation is to discover the grouping conduct of the speculators for the occasion of Swiss Franc unpegging. The MFDFA was utilized to contemplate the scaling conduct of non-stationary multifractal time arrangements right now. Non-stationary time arrangement as a rule experiences the ill effects of predisposition because of the adjustment in powerful mean worth. Accordingly, it is important to acknowledge the proof whenever there is a cycle of non-stationary multifractal elements. The principle behind this is to consider the deviation from the mean of polynomial alterations. The research has shown the dependability of alterations is time dependent. This additional worth was displayed through a stochastic procedure. This strategy gives data on the development of any money related time arrangement. The scale outline interprets this entire figuring into the notable Generalised Hurst Exponent (GHE). It has been discovered that such stochastic arrangement has a one of a kind scaling property defined by "H", which fits splendidly into one self refined example (or self-affinity type) for a similar time series. In any case, it was discovered that the quantitative estimation of selfunderstanding (Hurst coefficient or type) is consistent for each $\mathrm{q}^{\text {th }}$ order. Specialists found that GHE precisely closer to the genuine Hurst example (speaking to both pastoralism and air pocket) for $\mathrm{q}$ $=1$. It is because the higher class "q" was considered; both the GHE and MFDFA results are considered.

\section{Data Interpretation}

To develop the correlation between the two countries, the Granger Causality test was performed. Kyle \& Obizhaeva (2019) has briefly defined linear Granger Causality in a VAR system to explore informational linkages between pairs of markets. The $X_{t}$ and $Y_{t}$ for our test were BSE and SMI Index. The results showed that BSE is driven by SMI as the probability of the test was less than $10 \%$. The limit of probability is kept as $10 \%$ and not $5 \%$ because the test is conducted for a macroeconomic study. This includes $5 \%$ tail on each side thus making the limit to be $10 \%$. The results are inconsistent with the economic health of India. The bilateral trade relations also suggested that the Indian economy is dependent on the Swiss economy to some extent. 
The high-frequency data was divided into 79 small data packets, with a total observation of 8352. The iota value obtained from MATLAB was 12.08 which further gives the alpha decay greater than 3. The positive tail exponent for the index turns out to be 3.02. Risk and return were found to follow a similar power law connection. Stock markets are usually a specific form of long memory process having strong correlations with its lags. Such a high degree of auto-correlation indicates a higher degree of predictability.

Table: 1

\begin{tabular}{cc}
\hline Alpha Value & Interpretation \\
\hline$<3$ & Platykurtic, Information already in the market \\
3 & Normal Gaussian Distribution \\
$>3$ & Leptokurtic, Information Asymmetry \\
\hline
\end{tabular}

The acquired alpha worth is more than 3 which infers that the chart is leptokurtic and data of the Franc unpegging was not referred to by every single financial specialist as shown from the above table. If the worth had been under 3, this suggests the data about the occasion was known to each financial specialist of India and subsequently the effective market speculation was followed upon the arrival of $15^{\text {th }}$ January. It is exceptionally uncommon to get a proficient market in the genuine world, as each financial specialist doesn't have similar access to assets of data like others have. India is a nation with a gigantic hole of rich and poor and groundbreaking and non-ground-breaking brokers. This leads insider exchanging and therefore a few financial specialists have more information than the other which prompts asymmetry of data henceforth giving the alpha worth more prominent than 3 . Ordinary appropriations are uncommon in the genuine world; even the most productive market won't be as immaculate as Gaussian circulation. The appropriation here got exceptionally leptokurtic and along these lines fulfills that the occasion of unpegging was a fat-tail occasion. It has not just influenced the nation where it happened but also the nation which was monetarily connected with it. The data asymmetry in the Indian market drives us to look at the conduct of speculators. It is evident that a trace of 
herding behavior is present in Indian market. The presence of herding violates the law of "efficient market hypothesis". Grouping conduct is increasingly common during huge market developments in the two markets. In relative terms, a lower pervasiveness of grouping conduct was distinguished in the Indian securities exchange.
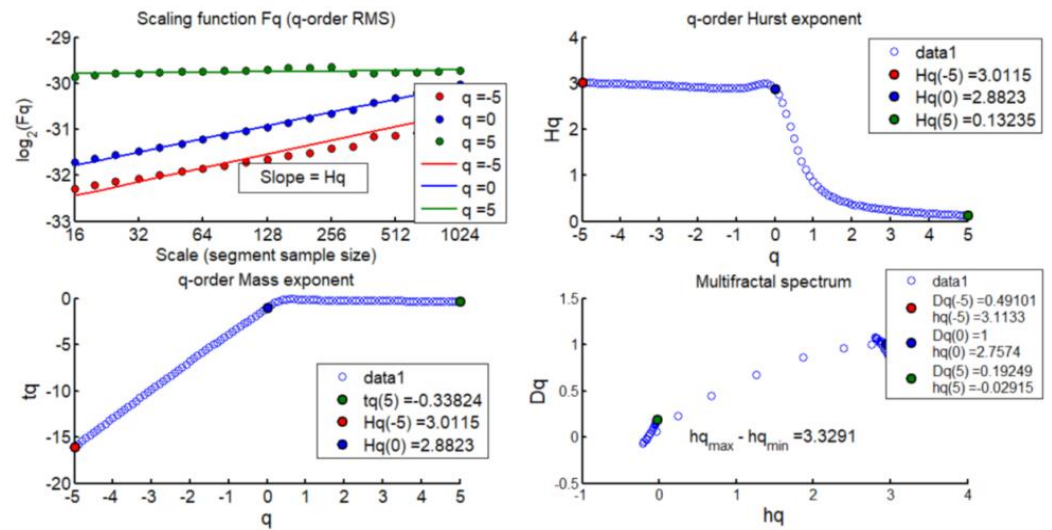

Fig: 3 qth order Hurst Exponent

The high-frequency data of the NIFTY 50 index was further taken into two lags lag1 and lag2 and was run in MATLAB with the codes MFDFA. A set of results were obtained out of which the above figure tends out to be a measure of the Hurst exponent which shows the herding behaviour in the market. The $\mathrm{q}^{\text {th-order }}$ Hurst exponent has been expressed as ' $\mathrm{Hq}^{\prime}$, for the time-series under consideration has been found to have various different traces; the multifractal one (blue trace), monofractal one (red trace), and finally white noise (turquoise trace), (Ihlen, 2012) where the coloured dots represent the slopes $\mathrm{Hq}$ for various order of the exponent such as $\mathrm{q}=-5,0,0$, and 5 .

Table: 2

\begin{tabular}{cc}
\hline Hurst Exponent & Interpretation \\
\hline$<0.5$ & Non-persistent, No Herd Behaviour \\
0.5 & Stochastic in nature \\
$>0.5$ & Persistent, Trace of Herd Behaviour \\
\hline
\end{tabular}


The Hurst exponent of the $5^{\text {th }}$ order is considered here and is found to be 0.02915 . The value of Hurst exponent is less than 0.5 which confirms that there was no herding behaviour amongst the investors on the unpegging day. The higher the data the higher is the persistence. The value of $\mathrm{H}>0.5$ indicates that there is a trace of herding behaviour and it is persistent. This means that the past can predict the future and hence follows the Bachelier model. The herding behaviour can also be confirmed with the below stated figure.

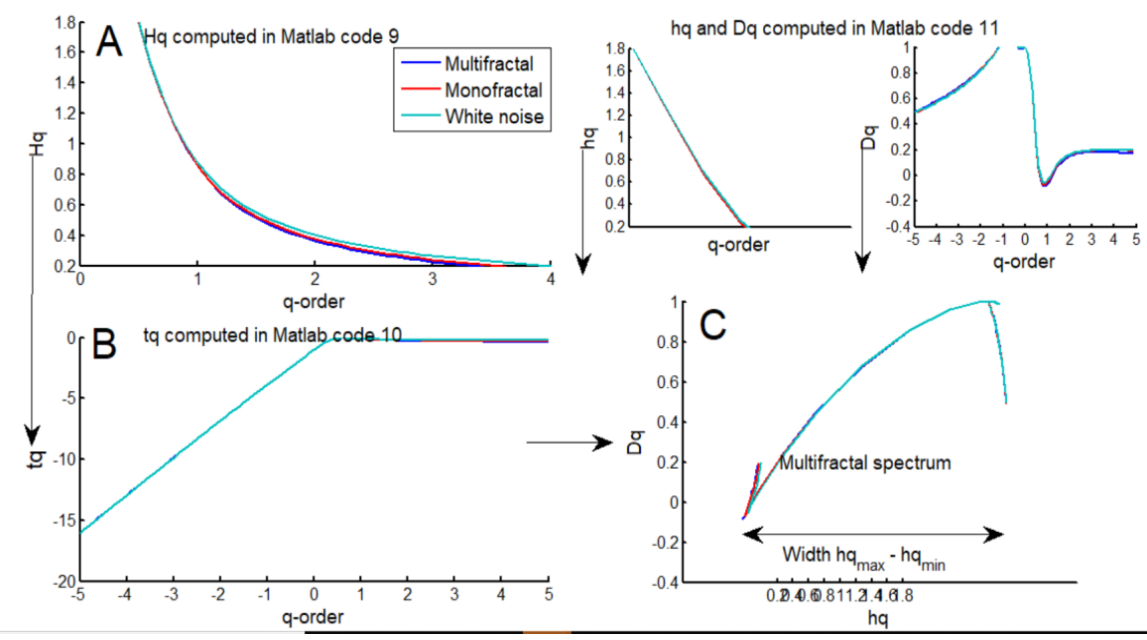

Fig: 4 The multifractal spectrum of time series

The above figure shows the parabola of the Multifractal spectrum. As observed from the diagram the parabola is not a complete inverse parabola. This results in no trace of herding behaviour on the fat-tail event day. The researchers have obtained a perfect inverse parabola for a fat-tail event for certain economies. The inverse parabola signifies the constant rate of acceleration and deceleration which shows that the market is highly volatile. The high volatile markets have hidden herding behaviour in it. The evidence of herding was not found on the event day, as the market was going down the Indian market has not shown herding. If it had been the case of upward movement of the market, herding behaviour might have been visible in the results. 


\section{Conclusion}

The world has become an interconnection of economies now. It is obvious that when the economies are in close connection, the events happening in either of the countries will affect the other either in a good way or a bad way. Switzerland is India's $5^{\text {th }}$ largest trading partner. The event of currency unpegging that occurred in Switzerland has immensely affected India. The event of Swiss Franc unpegging is confirmed to be a fat-tail event as the value of alpha decay is greater than 3 . This confirms the asymptotic decay of the NIFTY 50 index was seen by the turmoil on 15 th January 2015.

The two countries show a strong relationship in terms of economic bilateral trade relations. A huge amount of black money always leaves from India to Swiss Bank accounts. The correlation between the two countries cannot only be seen by bilateral trade agreements but also by Granger Causality. The correlation test shows that the Indian index is driven by the Swiss index. This means that any event which affects the Swiss market also tends to affect the Indian market. This is also possible as the FDI investments from Swiss are increasing rapidly. India is seen as an emerging economy for nations like Switzerland.

The fat-tail event is found to be leptokurtic. The market was found inefficient on the event day. The result can vary if the data size was increased and was taken for the whole day. As the data captures only the period when the index fell, it might be a case that the entire picture of the hidden behaviour of investors was not revealed. The herding behaviour of Indian investors was also found to be absent. The inverse parabola was perfectly not a parabola which confirms the herding effect. Also, the Hurst Exponent obtained was very low and was not able to breach the herding limit. Usually, herding behaviour is seen when the market goes up in the Indian economy. This can be a reason for the absence of herding behaviour.

It can be concluded that the geographical occurrence of events does not matter. If the economies are connected they are prone to fat-tail events even if it has not occurred in the country itself. Swiss Franc Unpegging is one of the classic examples that show how economies can be affected. The event had its effect on India for a short period 
which was captured by the high-frequency. The market showed the presence of information asymmetry and no trace herding amongst the investors.

\section{References}

Acharya, V. V. A., \& Yorulmazer, T. (2019). Information contagion and bank herding. Journal of Money, 40(1), 215-231.

Bachelier, L. (1900). Th'eorie de La Sp' Eculation. Annales Scientifiques de l'École Normale Supérieure, 17, 21-86.

Belke, A., \& Setzer, R. (2004). Contagion, herding and exchange-rate instability- A survey. Intereconomics, 222-228.

Bensaïda, A. (2017). Herding effect on idiosyncratic volatility in U. S. industries. Finance Research Letters, 3(1), 1-21.

Botta, F., Moat, H. S., Stanley, H. E., \& Preis, T. (2015). Quantifying stock return distributions in financial markets. PLOS ON, 10(9), 1-10.

Dungey, M., \& Tambakis, D. (2003). International financial contagion: What do we know ? Mardi Dungey \& Demosthenes Tambakis Comments, $9,1-23$.

Evangelista, J., \& Segovia, T. (2017). Introducing Hurst exponent in pair trading. Physica A: Statistical Mechanics and Its Applications, 1-14.

Fama, E. F. (2008). The behavior of stock-market prices. The Journal of Business, 38(1), 34-105.

Farmer, D., \& Geanakoplos, J. (2011). Power Laws in economics and finance. SSRN Electronic Journal, 1-57.

Gabaix, X. (2016). Power laws in economics: An introduction. Journal of Economic Perspectives, 30 (1), 185-206.

Ghorbel, A., Boujelbene, M. A., \& Boujelbene, Y. (2014). Behavioral explanation of contagion between oil and stock markets. International Journal of Energy Sector Management, 8(1), 121-144.

Ghosh, B., \& Kozarevic, E. (2018). Identifying explosive behavioral trace in the CNX Nifty Index: A quantum finance approach. Investment Management and Financial Innovations, 15(1), 209-223.

Ghosh, B., \& Kozarevic, E. (2019). Multifractal analysis of volatility for detection of herding and bubble: Evidence from CNX Nifty HFT. Investment Management and Financial Innovations, 16(3), 182-193.

Ghosh, B., \& Krishna, M. C. (2019). Power law in tails of bourse volatilityEvidence from India. Investment Management and Financial Innovations, 16(1), 291-298.

Ghosh, B., Mc, K., Kozarevic, E., \& Pandey, R. K. (2018). Predictability and herding of bourse volatility: An econophysics analogue. Investment Management and Financial Innovations, 15(2), 317-326. 
Ghosh, B., \& Nisha, N. (2018). Comparative volatility study on India VIX by Garch and Shannon entropy from a behavioural finance viewpoint. International Journal of Applied Business and Economic Research, 16(2), 317-324.

Gibrat, R. (1931). Les Inégalités Économiques; Ap- Plications: Aux Inégalités Des Richesses, à La Con- Centration Des Entreprises, Aux Populations Des Villes, Aux Statistiques Des Familles, Etc., d'une Loi Nouvelle, La Loi de l'effet Proportionnel. Libraire Du Recueil Sirey. Paris.

Gneiting, T., \& Schlather, M. (2001). Stochastic models which separate fractal dimension and Hurst effect. SIAM review, 1-8.

Hausdorff, F. (1918). Dimension and ausseres Mass. Mathematische Annalen, 79(1-2), 157-179.

Hill, B. M. (1975). A simple general approach to inference about the tail of a distribution. The Annals of Statistics, 3(5), 1163-1174.

Hurst. (1951). H.E.Long-term storage capacity of reservoirs. Trans. Am. Soc. Civ. Eng., 116, 770-799.

Ihlen, E. A. F. (2012). Introduction to multifractal detrended fluctuation analysis in Matlab. Methods Article, 3(June), 1-18.

Jansen, D. W., \& Vries, C. G. de. (1991). On the frequency of Large Stock Returns: putting Booms and Busts into Perspective. The Review of Economics and Statistics, 73(1), 18-24.

Jiang, Z., Xie, W., Zhou, W., \& Sornette, D. (2018). Multifractal analysis of financial markets Multifractal analysis of financial markets.

Kantelhardt, J. W., Zschiegner, S. A., Koscielny-bunde, E., Bunde, A., Havlin, S., \& Stanley, H. E. (2002). Multifractal Detrended Fluctuation Analysis of Nonstationary Time Series. Physica A: Statistical Mechanics and Its Applications, 316, 1-4.

Kim, M., \& Kim, M. (2014). Group-Wise Herding Behavior in Financial Markets : An Agent-Based Modeling Approach. PLOS One, 9(4), 1-7.

Kumar, A., Bharti, M., \& Bansal, S. (2018). An examination of herding behavior in an emerging economy - A study of Indian stock market. Global Journal of Management and Business Research: B Economics and Commerce, 16(5), 58-64. Kyle, A. S., \& Obizhaeva, A. A. (2019). Large Bets and Stock Market Crashes. (AFA 2013 San Diego Meetings Paper).

Linders, D., Dhaene, J., \& Schoutens, W. (2015). Option prices and modelfree measurement of implied herd behavior in stock markets. International Journal of Financial Engineering,02(02), 150012.

Mandelbrot, B. B. (1970). Comment on "Stochastic Models in Hydrology." Water Resour. Res., 6, 1791.

Mandelbrott, B. (2009). The Variation of Certain Speculative Prices. The Journal of Business, 36(4), 394-419.

Min, H., \& Hwang, Y. (2012). Dynamic correlation analysis of US financial 
crisis and contagion: evidence from four OECD countries. Applied Financial Economics, 22, 2063-2074.

Nirei, M., Stachurski, J., \& Stachurski, J. (2018). Herding and Power Laws in Financial Markets. CARF - F-434.

Ormos, M., \& Imotity, D. (2016). Market Microstructure During Financial Crisis: Dynamics of Informed and Heuristic-Driven Trading. Finance Research Letters, 1-15.

Parkinson, M. (1980). The Extreme Value Method for Estimating the Variance of the Rate of Return. The Journal of Business, 53(1), 31-65.

Redelico, F. O., \& Proto, A. N. (2012). Empirical fractal geometry analysis of some speculative financial bubbles. Physica A, 391(21), 5132-5138.

Riedi, R. H. (1999). Introduction to Multifractals. A Paradigm: The Binomial Measure, 1-23.

Watkins, N. W., \& Franzke, C. (2017). A brief history of long memory: Hurst, Mandelbrot and the road to ARFIMA, 1951-1980. Entropy, 19(437), 1-21.

$\mathrm{Wu}$, L. (2006). Dampened power law: Reconciling the tail behavior of financial security returns. The Journal of Business, 79(3), 1445-1473.

Zhang, C., \& Huang, L. (2010). A quantum model for the stock market. Physica A: Statistical Mechanics and Its Applications, 389(24), 5769-5775. 